\title{
A LUTA PELA LÍNGUA
}

\section{Eduardo Gusmão de Quadros*}

\author{
... a língua é a mais alta manifestação da \\ inteligência de um povo, é a sua criação mais \\ viva e original; e, portanto, a emancipação \\ política do país requer como complemento \\ e consequiência a sua emancipação \\ idiomática \\ Policarpo Quaresma, personagem \\ de Lima Barreto
}

\section{RESUMO}

O Diretório dos índios (1757) pretendia impor aos povos indígenas a utilização da língua portuguesa. Este artigo estuda o processo de substituição lingüística, não ocorrido completamente, e a resistência a tal processo na Amazônia. A defesa preparada pelo frei Manuel do Rosário, que foi acusado de permanecer pregando em "Nheengatu", é analisada, sendo esta uma fonte privilegiada para a compreensão dos confrontos surgidos.

Palavras-chave: Amazônia, línguas indígenas, missionários.

\begin{abstract}
The Directory of the Indians (1757) it intended to impose the indigenous people the use of the Portuguese language. In this article, we' re studied the process of linguistic substitution, that it didn't get to happen completely, and the forms of resistance appeared in the Amazonian. The prepared defense for friar Manuel do Rosário, accused by staying preaching in the "Nheengatu", it is analyzed, being an important source in the understanding of the confrontations.
\end{abstract}

Key-words: Amazônia, indigenous language, missionaries. 
Houve grande pilhéria na corte quando foi lida a petição do Major Quaresma. Nela, a personagem de Lima Barreto requisitava ao Congresso Nacional a instituição do "Tupi-guarani como língua oficial e nacional do povo brasileiro" (1972, p. 61). O idioma Português seria uma língua "emprestada", não propícia para expressar nossas belezas, nem nossas idéias. Já o Tupi, estava "adaptada perfeitamente aos órgãos vocais e cerebrais dos brasileiros" (1972, p. 61).

O romance é situado no período inicial da República. Nessa época, uma proposta de tal teor só poderia soar comicamente. A "Língua Brasílica" estava praticamente extinta, sendo falada apenas em pequenos lugares isolados, distantes do litoral. Toda uma luta, entretanto, esconde-se por trás da incorporação do idioma Português como língua nacional. $\mathrm{O}$ espaço privilegiado desses conflitos foram as missões.

A "Língua Geral falada pelos índios da costa do Brasil"1 era uma língua indígena e uma língua "missionária"(CÂMARA, 1977, p. 101 et seq.). Ela não foi produzida nas aldeias, mas foi sistematizada e difundida a partir delas. Os povos indígenas que a desconheciam, denominados genericamente de "tapuias", aprendiam-na logo ao serem descidos para os aldeamentos. O "Nheengatu", a "fala boa" dos povos Tupi, foi se tornando, dessa forma, a língua franca dos intercursos entre brancos e índios ou mesmo entre as diferentes nações indígenas.

Não só. Muitos brancos adotaram a Língua Geral. Alguns, dominavam apenas esta, chegando a desconhecer o Português. Em 1698, por exemplo, um governador de São Paulo pediu que fossem enviados à capitania exclusivamente padres com fluência na língua brasílica, pois de outro modo haveria necessidade de contratar um intérprete (RIBEIRO; MOREIRA NETO, 1992, p. 38). Isto não ocorreu apenas em São Paulo. A predominância da Língua Geral conservou-se por muito tempo no Estado do Maranhão e Grão-Pará. Na "Corografia Brasílica", Aires de Casal chega a afirmar, exagerando, que a língua portuguesa só começou a ser usada na região em 1755 (1976, p. 299). A data referida remete à redação do Diretório dos Índios. Este conjunto de leis sobre a administração dos povos nativos proi-

1 Utiliza-se como sinônimos os termos Língua Brasílica, Língua Geral ou Nheengatu, conforme aparecem na documentação. A exclusão do nome de Tupi-guarani, usado por Lima Barreto, se fez porque, como demonstrara Edelweiss, as duas línguas são bastante distintas, nunca tendo sido unificadas (1947, p. 165). 
biu a comunicação em Nheengatu. Depois dele, somente o idioma Português deveria ser escutado nas povoações.

Contra essa imposição levantou-se o padre mercedário Manuel da Penha do Rosário. Com experiência em várias aldeias e mais de dez anos de trabalho missionário na região amazônica, esse religioso escreveu uma veemente defesa sobre a utilização da "língua vulgar dos índios" na catequese. ${ }^{2}$ Através dela, legitimou sua prática e a de outros padres, conseguindo também safar-se da perseguição pombalina. Investiguemos os motivos que o levaram a lutar pela língua indígena.

\section{Colonizar e civilizar}

Primeiro é preciso saber: por que o regime liderado pelo Marquês de Pombal proibiu a utilização da Língua Geral? O texto do Diretório dos Índios (apud BEOZZO, 1993, p. 129-167) é bastante ríspido nas referências feitas a esta, chamando-a de "invenção verdadeiramente abominável e diabólica" (§ 6). Pelo texto da lei, portanto, a Língua Brasílica seria inventada. Por quem? Óbvio que não foi pelo diabo. O texto não deixa explícito, mas, considerando os combates do Marquês, fica claro que o termo referese metaforicamente à Companhia de Jesus. A imposição do português faz parte da cruzada antijesuítica do ministério pombalino, terminando com a supressão dos inacianos de todo o reino, em 1759. Essa identificação entre a obra missionária jesuítica e a Língua Geral seria correta?

Nas primeiras cartas enviadas do Brasil pelo padre Manuel da Nóbrega, encontramos referências à questão lingüística. A princípio, tal qual Colombo ao chegar na "América", ${ }^{3}$ o religioso não via claramente uma língua. Os nativos seriam "tão brutos que nem vocábulos tem" (1988, p. 73). Apesar disso, houve um esforço dos primeiros jesuítas para traduzir

2 “A defesa do Pe. Manuel da Penha do Rosário contra a imposição da língua portuguesa aos índios por meio de missionários e párocos (1773)" foi publicada por José Pereira da Silva nos Anais da Biblioteca Nacional, volume 113, 1993, página 7-62.

3 Desta forma interpreta Todorov (1999, p. 36) a afirmação do Diário de Cristóvão Colombo, onde o capitão pretende levar seis índios à Espanha para aprenderem a falar (1999, p. 53). 
algumas orações. Quem melhor se saiu nessa tarefa foi o padre Navarro, considerado o primeiro a por na Língua Brasílica algumas orações e diálogos catequéticos ${ }^{4}$ (VASCONCELOS, 1997, p. 199).

Como já haviam feito os missionários da América Espanhola (HOORNAERT, 1994, p. 402 et seq.), os religiosos da Companhia de Jesus do Brasil optaram por aprender as línguas indígenas, utilizando-as para o ensino e a administração dos sacramentos. Além de exercer seu ministério com maior eficácia, era perigoso confiar nos intérpretes, segundo advertência do padre José de Anchieta. Às vezes, o missionário pregava uma coisa e eles traduziam, justamente, o contrário (1988, p. 91). A adoção da língua dos nativos também foi induzida por problemas teológicos. Uma confissão feita por intérprete seria válida? Manuel da Nóbrega respondia afirmativamente, contudo o bispo recém chegado discordava (NÓBREGA, 1988, p. 141). O mesmo vale para as fórmulas de contrição ou a extrema-unção. Para surtirem efeito, deveriam ser compreendidas e pronunciadas com sincero arrependimento. Tal atitude seria bastante facilitada pelo uso da língua indígena, mas não com o português ou o latim.

Não é tão correta a acusação aos religiosos inacianos de adaptarem-se aos índios, deixando-os na "barbárie" e impedindo-lhes os meios para "civilizarem-se", feita pelo Diretório. ${ }^{5}$ Isso porque as escolas fundadas pelos jesuítas ${ }^{6}$ eram bilíngües, sendo ensinados português e latim (LEITE, 1965 , p. 40 et seq.).

Enquanto ensinavam aos "curumins", os missionários aprendiam a língua indígena. Nem todos, é verdade. Padre Nóbrega nunca a aprendeu. Mas Anchieta, do mesmo modo que o padre Navarro, também basco, logo se destacou no estudo da fala dos nativos. Prova de seu afinco foi a compo-

4 Na carta redigida seis meses após a que foi citada, Nóbrega registra os progressos lingüísticos de Navarro, não somente entendendo os índios, mas também pregando na língua deles (NÓBREGA, 1988, p. 105).

5 Continua o texto do sexto parágrafo dizendo: “...privados os índios de todos aqueles meios que os podiam civilizar, permanecessem na rústica, e bárbara sujeição...” (BEOZZO, 1993, p. 129-167).

6 Fundar escolas fazia parte do projeto catequético. Por isso, na maioria das aldeias elas existiam, ensinando os filhos dos naturais a ler e escrever. Através desse ensino, os missionários tentavam incutir nas crianças o desprezo pela cultura de seus pais. Anchieta, por exemplo, afirma enaltecendo os frutos da escola de Piratininga: "Temos uma grande escola de meninos índios, bem instruídos em leitura, escrita e em bons costumes, os quais abominam os erros de seus progenitores" (1988, p. 89). 
sição da primeira gramática do Tupi, ${ }^{7}$ em 1556, segundo os estudos de Hélio Viotti (1966, p. 61), dois anos após ter chegado. Em 1560, o superior da Companhia, Luís de Grã, tornou obrigatória a aprendizagem do idioma brasílico, sendo estudado através da obra de Anchieta. ${ }^{8}$

Lendo com os olhos contemporâneos, pode parecer normal a redação de uma gramática. Na época, era recente essa "arte" de organizar a língua falada através de regras. Não havia trinta anos que a primeira gramática do idioma português, composta pelo dominicano Fernão d'Oliveira, tinha sido impressa. Quatro anos após, em 1540, a gramática de João de Barros, bem mais sistemática, foi lançada (SILVA NETO, 1979, p. 489 et seq.). Esse era o momento de afirmação da Língua portuguesa, representado pelas defesas e elogios lançados durante todo o século XVI. ${ }^{9}$

O modelo dessas gramáticas, inclusive a de Anchieta, foi ainda o latim. As nações indígenas não falavam uma língua com tantas regras rígidas. Ao buscá-las, inspirando-se em uma língua européia, o jesuíta inseriu diversas modificações. A palavra "invenção" no texto do Diretório, possivelmente, refere-se a isso. As mudanças feitas, todavia, não podem ter sido muito grandes, pois, se assim fossem, a comunicação deixaria de ocorrer. A Língua Geral permanece sendo indígena, pois qualquer inovação deveria fazer sentido dentro do mundo cultural aborígine. ${ }^{10}$

Outro sentido da palavra "invenção" pode encontrar-se no status adquirido pela fala dos povos que habitavam a costa brasileira. Ao

7 O tupinólogo Carlos Drumond, na introdução à gramática de Anchieta, chama a atenção de que nessa época o Tupi ainda não havia se tornado a Língua Geral dos índios do Brasil (ANCHIETA, 1990, p. $5 \mathrm{~s})$.

8 Na carta escrita em 13 de setembro de 1560, Pe. João de Mello informa: "Logo que o padre (Luís de Grã) aqui chegou, ordenou que em casa se lesse a arte da língua brasílica que compôs o irmão Joseph (...) desta lição nem reitor, nem pregador, nem outra pessoa é isenta” (NAVARRO et al., 1988, p. 279).

9 Os títulos registrados por Wilson Martins dão uma idéia desse processo: "Regras que ensinam a maneira de escrever a ortografia da Língua Portuguesa acompanhado do Diálogo em defesa da mesma língua", de Gândavo; "Breves louvores da Língua Portuguesa", de Álvaro Ferreira de Vera; "Discurso das partes que há de haver na linguagem para ser perfeita e como as portuguesas as tem todas", de Manuel Severino (1992, p. 14).

10 Alguns autores como Mattoso Câmara, falam de um “aperfeiçoamento" que os missionários, na sua ótica, tentaram fazer (1977, p. 104). Exemplos da criação de novas palavras podem ser recolhidos da poesia anchietiana, onde aparecem "tupansy" (mãe de tupã), para referência a Nossa Senhora; "tupãtaýra" (filho de tupã), para Cristo. Além das criações partindo da mitologia, ele cria modificações verbais, como no caso do verbo "tekó" (vida, ser), adaptado do verbo "aikó" (eu sou, eu vivo). Ver ANCHIETA, J. de. Lírica portuguesa e tupi. São Paulo: Loyola, 1984. p. 84. 
sistematizá-la, os missionários acabaram por elevá-la ao mesmo nível de dignidade das outras línguas. Como ressaltou Schaden, na América Portuguesa não se formou um dialeto mestiço ou um português adulterado, mas, à medida que ia sendo incorporado, o elemento indígena conseguiu imprimir feições nativas ao conjunto sociocultural (1969, p. 165).

No processo de manutenção e difusão da Língua Brasílica, o trabalho missionário foi fundamental. ${ }^{11}$ Neste ponto, a legislação pombalina estava com razão. O celeiro de seu cultivo foram os aldeamentos. Mas por que os padres cederam? Eles não poderiam impor o idioma português, como faziam com as normas familiares, sexuais ou religiosas?

O Diretório dos Índios responde acusando-os de desejar o monopólio sobre a população nativa. ${ }^{12}$ Lembramos que, na região amazônica, onde esse conjunto de leis foi inicialmente aplicado, a Língua Geral era bastante conhecida. Os viajantes Spix e Martius, afirmam que até 1757 era essa a língua ouvida dos púlpitos nas igrejas de Belém (1976, p. 26). Os índios, portanto, não ficavam isolados dos moradores por não falarem português. Talvez, apenas das autoridades vindas há pouco tempo da metrópole.

Por outro lado, manter uma língua era, como ensina Bakhtin, preservar uma concepção da vida e do mundo (1993, p. 415). Os missionários possuíam a tarefa de converter as nações pagãs ao cristianismo, muito identificado na época com a cultura européia. Não é contraditório?

Um frade franciscano, Frei Martinho de Nantes, que não trabalhou com povos de Língua Geral, salientou um aspecto ainda não citado dentre os motivos da adoção da língua indígena pelos religiosos. Tendo escrito um dicionário e um catecismo na língua Cariri, Nantes colocou como essencial a aprendizagem do idioma nativo (1979, p. 43). Sem este, não se poderia averiguar nos índios e índias os verdadeiros frutos da conversão (1979, p. 19). Conforme estabelecera Foucault, do conhecimento nascem os mecanismos de controle e do controle nascem os mecanismos do conhecimento (1987, p. 30).

Até que ponto se estenderia o poder dos religiosos? Com esta questão podemos encontrar mais uma pista para compreender a conservação da

11 José H. Rodrigues, em um dos poucos estudos escritos sobre o tema por um historiador, escreveu que o "predomínio da língua geral firmou-se com os bandeirantes" (1985, p. 22). Não dá, destarte, a devida importância ao trabalho dos religiosos.

12 Ver o texto do sexto parágrafo já citado na nota 5. 
língua nativa. Nos textos escritos pelos missionários, ordinariamente nos deparamos com protestos contra o caráter "obstinado" dos ameríndios. A essa característica, soma-se a sua "fé instável". ${ }^{13} \mathrm{Ou}$ seja, os indígenas aderiam ao cristianismo sem abandonar completamente seus valores culturais. Os religiosos, pouquíssimos diante da enorme população aborígine, influenciavam o comportamento dos catequizados, incutiam alguns valores, podendo ter conseguido extirpar algumas práticas, porém não seriam capazes de apagar uma cultura. A Língua Geral falada pelos índios da costa do Brasil se impôs; bem como uma série de costumes, alimentos, objetos, técnicas e conhecimentos. ${ }^{14}$

Além desse fator, desconhecemos qualquer objeção à Língua Brasílica em si. Não era pecado utilizá-la. Nas fontes eclesiásticas, são encontradas observações quanto à imperfeição dos idiomas nativos para expressar alguns conceitos teológicos. ${ }^{15}$ Condenação, não. Nas cartas-régias sobre o dever de ensinar a língua portuguesa, são invocados, justamente, tais motivos teológicos. Em 12 de fevereiro de 1727, por exemplo, o rei ordenou ao superior das missões do Estado do Maranhão a obrigatoriedade da instrução, em todas as aldeias, do idioma português.

...pois se eles se pusessem práticos nela mais facilmente poderão receber os mistérios da fé católica, e ter maior conhecimento da luz da verdade, e com esta inteligência melhor executar em tudo o que pertencer ao meu real serviço e terem maior afeição aos mesmos portugueses. (MARANHÃO, 1948, p. 214).

\section{O Diretório dos Índios não faz dessa forma. Sua argumentação é eminentemente política.}

13 O "tesouro descoberto" do Pe. João Daniel, jesuíta expulso da Amazônia por discordar do Diretório, exemplifica essa descrição do "caráter" indígena. Fizemos a análise de suas representações em outro estudo (Quadros, 2000).

14 As "trocas" entre colonizadores e índios são bem documentadas e estudadas. Remetemos à obra "clássica" elaborada por Sérgio B. de Holanda (1994).

15 Em carta enviada ao Concílio de Trento pelos bispos do México, considerava-se vantajoso o ensino de espanhol aos índios, "porque nossa língua é tão distante da deles e a deles é imperfeita para explicar o que convém dar-lhes entender, o que através dos que ali (no colégio) são e serão ensinados, será mais inteiramente conseguido..." (apud SUESS, 1992, p. 814). Ainda assim, o Concílio considerou correto ensinar na língua vulgar, como se verá adiante. 


\title{
Civilizar e cristianizar
}

Especialmente após a obra de Fernando Novais, acostumamo-nos a ver na segunda metade do século XVIII a "crise do antigo sistema colonial" (1979). A colônia portuguesa nas Américas parecia estar caminhando, teleologicamente, para sua independência. Prova disso, seriam as revoltas separatistas que surgiram.

Há uma outra percepção desse período proposta por Capistrano de Abreu. Na periodização que elaborou para a história brasileira, o mestre cearense vê a época iniciada pelo governo do Marquês de Pombal em sentido inverso ao referido. Sua característica mais forte seria, precisamente, a consolidação do sistema colonial. As reformas administrativas, o incremento dos impostos, o reforço da fiscalização, as novas leis visavam assegurar o maior controle e lucro da metrópole sobre sua rica colônia (1975, p. 140 et seq.).

Nessa perspectiva, podemos entender melhor a imposição da língua portuguesa. O sexto parágrafo do Diretório inicia afirmando:

\begin{abstract}
Sempre foi máxima inalteravelmente praticada em todas as Nações que conquistaram novos domínios, introduzir logo nos povos conquistados o seu próprio idioma, por ser indisputável, que este é um dos meios mais eficazes para desterrar dos povos rústicos a barbaridade dos seus antigos costumes; e tem mostrado a experiência, que ao mesmo passo, que se introduz neles o uso da língua do Príncipe, que os conquistou, se lhes radica também o afeto, a veneração, e a obediência ao mesmo príncipe (apud BEOZZO,1983, p. 132).
\end{abstract}

Consolidar o império. Aumentar o domínio. Aportuguesar a colônia. Anular as culturas nativas. Tais idéias são coincidentes no trecho acima. E dentro do projeto mais amplo do Diretório, podem ser resumidas com uma só palavra: civilizar.

Os missionários não foram capazes de fazê-lo. Deixaram as nações com costumes "bárbaros" e uma língua "verdadeiramente abominável". O Estado assumiu o ensino dos índios, organizando escolas leigas nas aldeias, muitas elevadas à categoria de vila. Nesse novo arranjo, os religiosos perderam o poder de comando que exerciam, substituídos pelos direto- 
res. As medidas visavam integrar mais eficazmente os índios ao império luso, transformando-os em perfeitos cidadãos.

Uma das tarefas importantes dos diretores era vigiar suas povoações, "não consentido por modo algum, que os meninos, e meninas, que pertencem às escolas, e todos aqueles índios, que forem capazes de instrução nesta matéria, usem da língua própria as suas nações, ou da chamada geral; mas unicamente da portuguesa".

As razões alegadas para o uso exclusivo do idioma português são eminentemente políticas. Contudo, desobedecer à Ordem Régia era considerado crime e pecado. Não apenas a autoridade régia foi instituída por Deus; o rei, pelo regime do padroado, ${ }^{16}$ é também chefe da igreja portuguesa. Os missionários, funcionários estatais, não poderiam mais catequizar e ministrar os sacramentos em Nheengatu. ${ }^{17}$

Discordava o frei Manuel do Rosário. Pecado seria deixar tantos indígenas morrerem pagãos. Explicar os princípios do cristianismo na própria língua dos nativos era sua obrigação. Essa convicção advinha da suprema autoridade em matéria de fé: o concílio tridentino. Suas constituições recomendavam ao clero o ensino da doutrina cristã "segundo a capacidade dos que o percebem", explicando na "língua vulgar as sagradas palavras e os avisos da salvação" (apud ROSÁRIO, 1993, p. 21).

O religioso fora denunciado aos governantes por assim agir. Através das "Questões apologéticas" se defendeu. O primeiro argumento, invocando Trento, já colocava a autoridade eclesiástica acima da real. Talvez, não exatamente acima, pois o trono e o altar não deveriam contradizer-se. Ele os separa. Se a igreja recomendava o ensino na língua vulgar dos povos, isto não podia ser alterado por nenhuma lei secular.

Um meio termo lingüístico poderia ser possível. Quando os índios não soubessem português, o padre os instruiria na língua lusa e posteriormente traduziria. Porém isso seria mais "gramático do que evangélico,

16 O padroado foi estabelecido pela bula "Romanus Pontifex" do Papa Nicolau V, em 1454. O rei de Portugal, como grão-mestre da Ordem de Cristo, recebeu o direito de administrar espiritualmente as novas terras conquistadas. O texto pode ser lido na obra documental organizada por Ribeiro e Moreira Neto (1992, p. 65-66).

17 Notemos que continuaram a haver missionários pagos pelo governo nas vilas. A secularização, apontada por muitos estudiosos como uma das idéias centrais do Diretório, deve ser compreendida em seu sentido restrito de lenta separação entre os níveis político, civil e religioso, não como decadência da religião. Sobre tal conceituação e suas transformações ver: MARRAMAO, G. Céu e terra. São Paulo: Ed. Unesp, 1997. 
cristiano e eclesiástico", respondeu o frei mercedário (ROSÁRIO, 1993, p. 22). Se tão difíceis eram as conversões verdadeiras catequizando na Língua Geral, mais difíceis seriam doutrinando-os de modo incompreensível para depois tornar inteligível. E de que valeria tanto trabalho, tanto desperdício de tempo? E quando o último não estivesse disponível? No caso do sacramento da extrema-unção, aplicado na hora da morte, "quando todo o inferno se empenha a que os homens se condenem", os índios deveriam entender as palavras de contrição e expressar tal sentimento. $O$ padre arriscaria perder aquela alma por questões tradutórias?

Talvez, escreveu frei Manuel, poderíamos esperar do Espírito Santo de Deus algo como o ocorrido em pentecostes (Atos, 2:1-11). A pregação não deve, entretanto, ficar na "dependência dos milagres". O Pentecostes, por sinal, foi precisamente tornar compreensível uma língua desconhecida para os povos estrangeiros, a fim de salvá-los (ROSÁRIO, p. 23).

O problema de aplicar a lei como foi entendida é que os povos indígenas, mesmo na época de redação da defesa do frade (1773), permaneciam desconhecendo o idioma português (ROSÁRIO, p. 25-33 passim). O projeto do Diretório de fundar "escolas públicas" não fora efetivado. ${ }^{18}$ Igualmente, a extirpação da Língua Brasílica nas vilas. Nem "venialmente" pecariam os párocos ensinando a lei de Deus aos índios na sua língua vulgar. Ao contrário, eles mereceriam ganhar "os prêmios que se prometem aos que fazem a divina vontade e guardam os preceitos de Deus" (ROSÁRIO, p. 28).

A aplicação ipsi literis da lei estava tão fora da realidade que o próprio frade propõe uma interpretação para torná-la viável. O idioma português seria exclusivo somente nas escolas, com os meninos e meninas aprendizes da língua. O código legislativo não compreendia os párocos ou a sua obrigação de instruir espiritualmente (ROSÁRIO, 1993, p. 38). Se não fosse delimitada, os diretores estavam incidindo constantemente em crime, pois tratavam com os nativos ignorantes da fala lusa em língua indígena (ROSÁRIO, 1993, p. 40).

Das dez questões elaboradas por frei Manuel do Rosário para desenvolver sua argumentação, as cinco primeiras tratavam da língua a ser utilizada na catequese. As cinco restantes discutiam se era pecado ensinar

18 O texto fornece dados. Na região do Gurupá e do rio Xingu, só havia uma povoação com escola: Pombal. Na região do Tapajós e do Amazonas nenhuma organizada (ROSÁRO, 1993, p. 42). 
em uma língua diferente da portuguesa a partir da legislação pombalina. Um dos eixos de discussão era, portanto, a relação estabelecida no Diretório entre língua e pecado. No pensamento do autor, esta conexão não existia. Era inventada. Não havia uma língua "diabólica".

Para provar sua convicção, o religioso fundamentou-se em textos bíblicos, nos documentos eclesiásticos, em cartas pastorais dos bispos diocesanos e na tradição da igreja. A teologia estava em primeiro plano, sendo que as leis portuguesas deveriam ser abordadas somente depois. Destarte, frei Manuel aproveitou-se da "secularização" promovida pelo ministério pombalino para reafirmar a autoridade eclesiástica. A lei não devia interferir na salvação dos povos ou, em palavras textuais,

...os párocos com suas instruções não estão sujeitos ao Diretório dos Índios, senão às determinações do prelado diocesano, cujo diretório é o Concílio Tridentino, com as constituições do bispado e suas pastorais e provisões (ROSÁRIO, 1993, p. 44).

Foi afirmado, entretanto, que a desobediência civil era crime e pecado. $\mathrm{O}$ conflito perpassou as representações, bem como a significação dada às práticas sociais. Os grupos em conflito estabeleceram táticas para fazer valer na configuração social sua concepção de mundo. ${ }^{19}$ Nesse sentido, mais do que "secularizar" através do Diretório, a monarquia portuguesa pretendia utilizar a instituição eclesiástica em seu projeto civilizatório. ${ }^{20}$

Isto foi percebido pelo padre. $\mathrm{O}$ segundo eixo de sua argumentação era a distinção entre cristianização e civilização. $O$ monarca continuou a enviar missionários para as vilas, demonstrando seu desejo de evangelizálos. ${ }^{21}$ Mas a tarefa de civilizá-los, afirmava Rosário, pertencia às escolas e aos professores, não aos párocos. "O referido e anotado parágrafo sexto não respeita, torno a dizer, ao cristianismo dos índios, senão só a sua civili-

19 Esta pesquisa baseia-se no instrumental teórico da "História Cultural". Seus principais conceitos encontram-se em Chartier (1990) e Certeau (1994).

20 A análise do Diretório dos Índios como um "projeto de civilização" é tese central da obra de Rita H. de Almeida (1997). A autora, contudo, não observa a função da igreja nesse projeto.

21 Lê-se, no terceiro parágrafo do Diretório: “...sendo evidente, que as paternais providências do nosso augusto soberano, se dirigem unicamente a cristianizar e civilizar estes até agora infelizes e miseráveis povos..." (apud BEOZZO,1983, p. 132). 
dade" (ROSÁRIO, 1993, p. 37). O religioso podia pregar e ministrar os sacramentos usando a Língua Geral sem nenhuma culpa, tanto diante da legislação estatal quanto da eclesiástica:

\begin{abstract}
...se-me mandou a ensinar e a instruir as coisas do céu e não a civilidade, pertencentes às escolas seculares e políticas, segundo os termos e os limites e esferas do Evangelho e do Sagrado Concílio de Trento e, também, conforme ao agrado e desejos do Espírito Santo, cujos instrumentos sãos os vigários e pregadores evangélicos e não ao beneplácito dos homens a ensinar a Arte Portuguesa, cujos mestres são os que a providência rela mandou pelo Diretório deputar e premiar (ROSÁRIO, 1993, p. 48).
\end{abstract}

Encontramos nesse trecho sintetizados os elementos principais do discurso de defesa do frade Manoel do Rosário: a prioridade normativa dos Concílios eclesiásticos, a não pecabilidade por ministrar doutrina ou sacramentos na Língua Brasílica, a autonomia do poder religioso perante o secular e a separação entre conversão e civilização. Idéias em confronto direto com as do poderoso primeiro-ministro de D. José I; idéias que garantiram sua absolvição diante do visitador inquisitorial Dr. Geraldo José de Abranches.

\title{
Quem venceu?
}

Em 1795, mais de cem anos após seu lançamento, foi impressa em Lisboa a quarta edição da "Arte da Gramática da Língua do Brasil”, composta pelo padre jesuíta Luís Figueira. Ao contrário do que afirmou Martins, não era uma obra "anacrônica", feita para uma "catequese impossível" (1992, p. 534). Nos primórdios do século XIX - com o Diretório revogado (1798) - a Língua Geral continuou a vigorar no "sertões", conforme registro admirado de Spix e Martius (1976, p. 36). Mesmo nas maiores cidades, o Português era pouco falado entre a população mestiça e indígena pelos idos de 1850 (RODRIGUES, 1985, p. 39). A língua dos conquistadores ainda não havia vencido. 
Vislumbramos, neste estudo, alguns aspectos desse prolongado processo de estabelecimento do idioma luso. Apesar da importância, é um tema pouquíssimo abordado pelos historiadores, como ressaltou Peter Burke (1993, p. 11). Estão envolvidos nele diversos elementos, tendo mais destaque o trabalho dos missionários católicos e as aldeias que fundaram.

A análise dos motivos alegados pelo mercedário Manuel da Penha do Rosário para permanecer catequizando na Língua Brasílica, após o Diretório dos Índios tentar extirpá-la, traz à luz alguns traços dos confrontos vividos. Revela uma luta não somente política, mas principalmente travada no mundo das representações sociais; um esforço para manter práticas e significá-las diferentemente do modo proposto pelo poder estatal.

Os povos indígenas, talvez os grandes responsáveis pela perpetuação de uma língua nativa, quase não apareceram no papel de sujeitos dessa história. Sinal de que a pesquisa ainda precisa caminhar muito, explorando novos métodos e fontes.

\section{Referências}

ABREU, J. C. de. Ensaios e estudos - v. 1. Rio de Janeiro: Civilização Brasileira, 1975.

ALMEIDA, R. H. O diretório dos índios. Brasília: Ed. UnB, 1997.

ANCHIETA, J. de. Arte de gramática da língua mais usada na costa do Brasil. São Paulo: Loyola, 1990.

ANCHIETA, J. de. Cartas, informações, fragmentos históricos e sermões. Minas Gerais: Itatiaia, 1988.

ANCHIETA, J. de. Lírica portuguesa e tupi. São Paulo: Loyola, 1984.

BAKTIN, M. A cultura popular na Idade Média e no Renascimento. São Paulo: Hucitec, 1993.

BARRETO, L. Triste fim de Policarpo Quaresma. São Paulo: Brasiliense, 1972.

BEOZZO, J. O. Leis e regimentos das missões. São Paulo: Loyola, 1983.

BURKE, P.; PORTER, R. (Org.). Linguagem, indivíduo e sociedade. São Paulo: Ed. Unesp, 1993. 
CASAL, M. A. de. Corografia brasílica. Minas Gerais: Itatiaia,1976.

CERTEAU, M. de. A invenção do cotidiano. Rio de janeiro: Vozes, 1994.

CHARTIER, R. História cultural. Rio de Janeiro: Bertrand do Brasil, 1990.

COLOMBO, C. Diários da descoberta da América. Porto Alegre: L \& PM, 1999.

EDELWEISS, F. Tupis e guaranis. Bahia: Secretaria de Educação e Saúde, 1947.

FOUCAULT, M. Vigiar e punir. Petrópolis: Vozes, 1987.

HOLANDA, S. B. de. Caminhos e fronteiras. São Paulo: Cia. das Letras, 1994.

HOORNAERT, E. História do cristianismo na América Latina e no Caribe. São Paulo: Paulus, 1994.

LEITE, S. Suma histórica da Companhia de Jesus no Brasil (1549-1760). Lisboa: Junta de Investigações do Ultramar, 1965.

MARANHÃO. Livro grosso do Maranhão. Rio de Janeiro: Anais da Biblioteca Nacional, 1948.

MARRAMAO, G. Céu e terra. São Paulo: Ed. Unesp, 1997.

MARTINS, W. História da inteligência brasileira - v. 1. São Paulo: T. A. Queiroz, 1992.

NANTES, M. de. Relação de uma missão no rio São Francisco. São Paulo: Nacional, 1979.

NAVARRO et al. Cartas avulsas - v. 2. Minas Gerais: Itatiaia, 1988.

NÓBREGA, M. da. Cartas jesuíticas - v. 1. Minas Gerais: Itatiaia, 1988.

NOVAIS, F. A. Portugal e Brasil na crise do antigo sistema colonial. São Paulo: Hucitec, 1979.

QUADROS, E. Os batinas e os brutos. Fragmentos de Cultura, Goiânia, n. 10, p. 927-941, set./out. 2000.

RIBEIRO, D.; MOREIRA NETO, C. A fundação do Brasil. Rio de Janeiro: Vozes, 1992.

RODRIGUES, J. H. História viva. São Paulo: Global, 1985.

ROSÁRIO, M. da P. Língua vulgar versus língua portuguesa: a defesa do Pe. Manuel da Penha do Rosário contra a imposição da língua portuguesa aos índios por meio de missionários e párocos. Rio de Janeiro: Anais da Biblioteca Nacional, 1993. n. 113 , p. 7-62. 
SILVA NETO, S. da. História da língua portuguesa. Rio de Janeiro: Presença, 1979.

SILVA NETO, S. da. Introdução ao estudo da língua portuguesa no Brasil. Rio de Janeiro: Presença, 1986.

SPIX, J. von; MARTIUS, C. von. Viagem pelo Brasil - v. 3. São Paulo: Melhoramentos, 1976.

SUESS, P. A conquista espiritual da América. Rio de janeiro: Vozes, 1992.

TODOROV, T. A conquista da América. São Paulo: Martins Fontes, 1999.

VASCONCELOS, S. de. Crônica da Companhia de Jesus. Rio de Janeiro: Vozes, 1977.

VIOTTI, H. A. Anchieta, apóstolo do Brasil. São Paulo: Loyola, 1966. 